\title{
Factors Affecting Patient's Satisfaction with Provided Sexually Transmitted Infections Primary Health Care Service in El-Damazin Locality at Blue Nile State, Sudan 2015 - 2016
}

\author{
Khalid Fadl Alla Khalid ${ }^{1}$, Samia Yousif Idris Habbani ${ }^{2}$, Nada Jafar Osman ${ }^{3}$, \\ Malaz Elbashir Ahmed ${ }^{1}$, Rania Hassan Abdelgfour ${ }^{1}$ \\ ${ }^{1}$ HIV Prevention Program, United Nations Population Fund, Khartoum, Sudan \\ ${ }^{2}$ Free Lance Community Medicine Consultant, Khartoum, Sudan \\ ${ }^{3}$ Primary Health Care Directorate, Federal Ministry of Health, Khartoum, Sudan
}

Email address:

elmalkey2011@gmail.com (K. F. A. Khalid), samiahabbani8@gmail.com (S. Y. I. H. Ani), nadajafar@gmail.com (N. J. Osman), malazbashirahmed@hotmai.com (M.E.Ahmed),drraniahassan@gmail.com (R.H. Abdelgafour)

\section{To cite this article:}

Khalid Fadl Alla Khalid, Samia Yousif Idris Habbani, Nada Jafar Osman, Malaz Elbashir Ahmed, Rania Hassan Abdelgfour. Factors Affecting Patient's Satisfaction with Provided Sexually Transmitted Infections Primary Health Care Service in El-Damazin Locality at Blue Nile State, Sudan 2015 - 2016. World Journal of Public Health. Vol. 3, No. 3, 2018, pp. 93-98. doi: 10.11648/j.wjph.20180303.14

Received: August 4, 2018; Accepted: August 22, 2018; Published: September 25, 2018

\begin{abstract}
Sexually Transmitted Infections (STIs) continued to be a significant public health problem especially among women at reproductive age and young people. Measuring patient satisfaction is an essential aspect of making services attractive to patients and improving the quality of service. This study was intended to explore the factors affecting the patients satisfaction with the provided STIs service at the primary health care (PHC) in El-Damazin locality at Blue Nile State (BNS) in Sudan, 2015 -2016. This study was analytical cross-sectional health facility-based study. This study revealed that the more than half of studied STIs patients were females, more than $40 \%$ were at the age of 25 years or less and single. Majority of studied patients stated that the PHC centers were accessible, and the service is affordable. More than $60 \%$ rated the patientscare providers (CPs) communication pattern as good, yet more than $50 \%$ of the single STIs patients, and more than $40 \%$ of the young patients' did not receive education and counseling on condom. Also, more than $60 \%$ of the illiterate patients did not receive education and counseling for HIV. Though the study showed that more than $60 \%$ were satisfied with provided service, the validation of this satisfaction those patients were not fully aware of their rights to communicate and discuss their cases with health CPs, even how to deal with the community and to receive all component of STIs service without discrimination. Based on the results, increase the demand for the STIs service by increasing the awareness of the local community to the STIs service delivery components, STIs/HIV prevention measure is essential. Also, adoption of the right based approach in the awareness raising will increase the demand on the STIs services components by decreasing the cultural silence about the STIs and selfstigma or stigma on health care setting.
\end{abstract}

Keywords: Sexually Transmitted Infections, Primary Health Care, Patient Satisfactions,

Education and Counseling on Condom, Education and Counseling for HIV Testing,

Patients- Care Providers Communication Pattern, Duration Time to Reach the Service,

Payment for Receiving the Service

\section{Introduction}

Sexually Transmitted Infections (STIs) are the most familiar group of notifiable infectious diseases in most developing and developed countries [1]. STIs epidemics', and their relation with the sexual activities are mentioned in the early scientific evidences [2-3]. World Health Organization (WHO) reported $85 \%$ of STIs cases occur in 
non-industrialized countries. The highest incidence rate of STIs cases has in sub-Saharan Africa, where the STIS incidence rate among adult between 15 to 49 years was 256 per 1000 in 2015 [4, 5, 6]. Nathlee Samantha Abbai et al, in 2013 illustrated that STIs continued to be a significant public health problem especially among young and the low educated women in the most African countries [7]. Also, Klouman et al. in Tanzania found the STIs considerably affected $78.6 \%$ of the studied women [8]. Other studies indicated that the sex and age are a factors that increase vulnerability to acquire STIs by the population and significantly associated with partner treatment [9-10]. Moreover, STIs facilitate the sexual transmission of HIV indirectly, lead to cellular changes that precede some cancers, and are important causes of infertility worldwide [4-6, 11].

There is an increasing body of evidence in Sudan indicating an increasing number of cases of sexually transmitted diseases, which are often obtained through heterosexual transmission. In 2010, syphilis prevalence was $2.3 \%$ among pregnant women attending antenatal care [not published]. The Sudan Database for Control of Communicable and Non-Communicable Diseases (CNCDCD) has shown that there are more than 60,000 cases of sexually transmitted infections in 2012 [not published]. The level of knowledge among the general population on HIV / AIDS and sexually transmitted diseases and selfprotection measures is low [12]. The 2012 integrated BioBehavioral Surveillance survey (IBBS), showed that the prevalence of syphilis is $27,9 \%$ among the most at risk women and $15 \%$ among most at risk men across the country with a geographical difference [13].

Measuring patient satisfaction is an essential aspect of making services attractive to patients and improving the quality of service [14]. Two hundred university students and university health care staff in Kwazulu-Natal at South Africa were interviewed to explore to what extent interpersonal relations between the care providers and patients form a barrier for young people's to access and to satisfy with provided health services. The results indicated the young people were aware of the importance of utilizing STI, HIV and family planning services but they experienced barriers in their relationship with providers and this served as a warning to their use of the health facility [15]. Other study revealed that most of the studied HIV-positive patients' patients were pleased with their current primary care physicians because of a good physician-patient relationship that tended to promote adherence to treatment [16]. Therefore, adequate training in interpersonal relations for youth-friendly service provision, and determine the themes regarded by patients as priorities for delivering a quality service are essential in helping overcome communication problems, enabling providers to interact with young clients at a more personal level, and to deliver quality health services [15-17].

The fifth population and household census -2008, reported a total of 329,845 population at the reproductive period (15 to 44 years) in BNS. The prevalence rate of STIs was $1 \%$ among them in 2012(around 3,298 cases) [13]. The BN-
SMOH report in 2012, indicated that only $35 \%$ of the estimated STIs cases received STIs health services, and this raising the questions regarding the barriers of not obtaining the STIs health services by the needy population. In the recent period there no study conducted to identify the patient satisfactions' with primary health care service in the BNS. This paper was intended to measure the patient satisfactions' with sexual health services; and specifically to explore factors affecting patient's satisfaction with provided STIs service in the PHC centers in El-Damazin locality at BNS during $2015-2016$.

\section{Methods}

a. Study Design: This study was descriptive, analytical, and cross-sectional health facility-based study applied both and qualitative quantitative research methods.

b. Study area: The study area was El-Damazin locality in BNS.

c. Study population: In this paper, the researcher has got two study populations:

d. STIs Patients' above 18 years of age who approached the PHC centers during the study period seeking STIs care and treatment.

e. STIs patient's below 18 years of age who approached the PHC centers during the study period seeking STIs care and treatment.

f. Sampling method and sample size: The simple random method was used to select STI patients. All STI patients attended the PHC centers between 9:00 am and 15:00 pm during the study period were targeted. The sample size was calculated using the below formula:

$$
n=\frac{N * Z 2 * P(1-P)}{(N-1) d 2+Z 2 * P(1-P)}
$$

Therefore, the sample size was 219 STIs patients.

\subsection{Data Collection Tools}

a. A pre- structured questionnaire "Intervieweradministered questionnaires" used to collect data from STIs patients under study.

b. A pre designed case problems with symptoms and signs on STIs used to collect data regarding the knowledge of CPs on syndromic diagnosis of STIs.

c. The patients reported outcomes (PROs) or experiences used to collect data regarding the patients' satisfaction with the provided STIs service.

\subsection{Data Collection Methods}

a. The method used to collect data from the STIs was direct face to face interview with open and close ended questions. The STIs patients interviewed by the trained data collectors. The average length of the interviews ranged between 35 to 45 minutes.

b. The method used to collect data about patients satisfaction was direct open question regarding their 
satisfaction of the provided service. Then collected data categorized into four levels; Very satisfied, satisfied, to some extent satisfied and not satisfied.

\subsection{Data Quality Assurance}

a. The data collectors were trained on the study tools, methods of data collection, and the ethical approach to obtain the data from the patients under the study.

b. The data collection process supervised by team supervisor to ensure the appropriate approach to interview the STIs patients was used by the data collectors.

c. The data collectors had a regular weekly meetings to review the number of filled questionnaires and to stand on the quality of data obtained, and any questionnaire with inconsistent data rejected by the team (Two hundred and twenty-four questionnaires were collected, and five questionaries' rejected by team due to inconsistent data).

d. Data cleaned manually by examining the collected raw data during which errors were detected and corrected by omission.

\subsection{Data Analysis}

Patterns or trends measured by descriptive statistics and inference of data about the general population measured by inferential statistics. Statistical analysis done by the following stages: data cleaned manually by examining the collected raw data during which errors were detected and corrected by omission, data entered into computerized software package SPSS for window version 20. General analytical analysis "cross tabulation, graphs and the frequency", and significant relationships between the variables produced by cross tabulation were performed by applied the test of significance "chi-square test used and Pvalue of $0.05 \%$.

\section{Results}

The results in this section got from the analyzed data of the studied STIs patients $(n=219)$. The results showed that the $51.1 \%(n=112)$ of studied patients were female, $41.5 \%(n=$ 90) were below the age of 25 years [Mean age is 27 and median age is 26], $48.4 \%(n=106)$ were single, $17.1 \%(n=$ $37)$ were students, and $25.6 \%(n=56)$ were the illiterate. Figure one showed that the $62 \%(n=136)$ of the studied STIs patients received education and counseling on condom, and $63 \%(n=137)$ were received education and counseling for HIV testing.

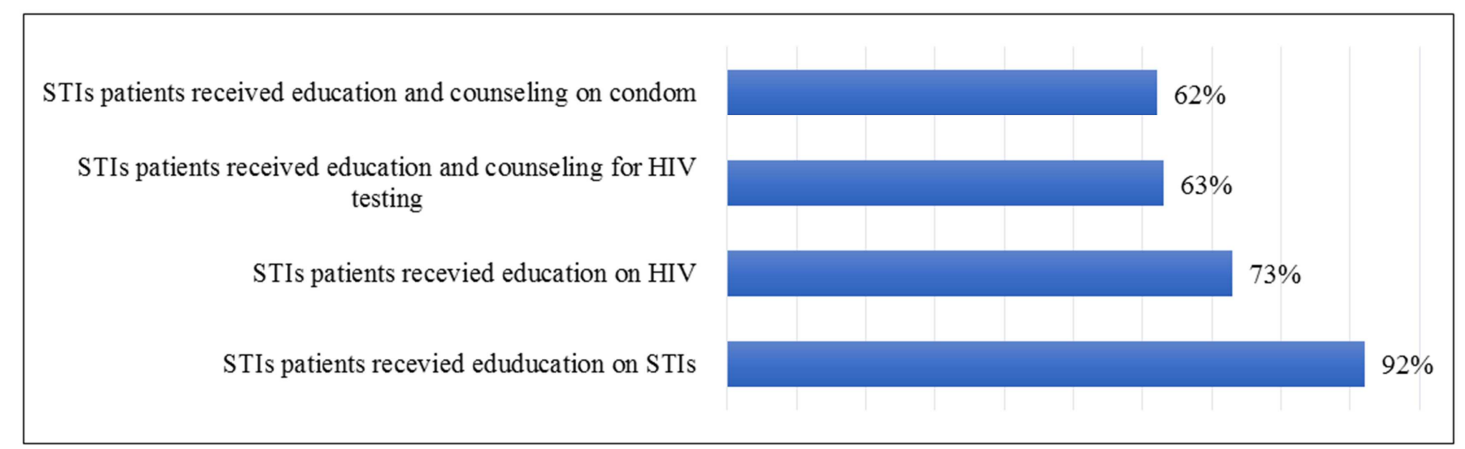

Figure 1. Type of health education and counseling received by STIs patients at PHC centers in El-Damazin locality at BNS, 2015-2016 ( $n=219)$.

The results indicated that the $49.4 \%(n=44)$ of patients below the age of 25 years, and $52.4 \%(n=55)$ of single patients did not receive education and counseling on condom respectively. The analysis indicated the significant association of marital status to the received education and counseling on condom [P value: 0.000 (2- sided)]. Also, the results showed that the $66.1 \%(n=37)$ of the illiterate STIs patients did not receive education and counseling for HIV testing, and the analysis indicated the significant association of educational level with the received education and counseling for HIV testing [P value: 0.000 (2- sided)].
Sixty-four percent $(n=140)$ of the studied STIs patients were satisfied with provided STIs services. The statistics in table. 1 showed that the $55.9 \%(n=76)$ of the patients who received education and counseling on condom, and $56.2 \%$ $(n=77)$ of those who received education and counseling for HIV testing were satisfied with the received education and counseling services. The analysis indicated the significant association of the provided education and counseling on condom and for HIV testing with the overall satisfaction of the provided service [P value: 0.000 (2- sided) respectively].

Table 1. Relationship between the health education and counseling services received by the STIs patients and the overall satisfaction of the provided STIs services at PHC centers in El-Damazin locality at BNS, 2015 - $2016(n=219)$.

\begin{tabular}{|c|c|c|c|c|c|c|c|}
\hline \multirow{2}{*}{ Details } & & \multicolumn{5}{|c|}{ Overall satisfaction of the provided service } & \multirow{2}{*}{ P value } \\
\hline & & Very satisfied & Satisfied & Satisfied to some degree & Not satisfied & Total & \\
\hline \multirow{4}{*}{$\begin{array}{l}\text { Received education and } \\
\text { counseling on Condom }\end{array}$} & Yes & 40 & 76 & 20 & 0 & 136 & \multirow{4}{*}{.000} \\
\hline & & $29.4 \%$ & $55.9 \%$ & $14.7 \%$ & $0.0 \%$ & $100.0 \%$ & \\
\hline & No & 0 & 64 & 17 & 1 & & \\
\hline & & $0.0 \%$ & $78.0 \%$ & $20.7 \%$ & $1.2 \%$ & $100.0 \%$ & \\
\hline
\end{tabular}




\begin{tabular}{|c|c|c|c|c|c|c|c|}
\hline \multirow{4}{*}{ Details } & & \multicolumn{5}{|c|}{ Overall satisfaction of the provided service } & \multirow{4}{*}{$P$ value } \\
\hline & & Very satisfied & Satisfied & Satisfied to some degree & Not satisfied & Total & \\
\hline & \multirow[t]{2}{*}{ Total } & 40 & 140 & 37 & 1 & 218 & \\
\hline & & $18.3 \%$ & $64.2 \%$ & $17.0 \%$ & $.5 \%$ & $100.0 \%$ & \\
\hline \multirow{6}{*}{$\begin{array}{l}\text { Received education and } \\
\text { counseling for HIV testing }\end{array}$} & \multirow[t]{2}{*}{ Yes } & 40 & 77 & 20 & 0 & 137 & \multirow{6}{*}{.000} \\
\hline & & $29.2 \%$ & $56.2 \%$ & $14.6 \%$ & $0.0 \%$ & $100.0 \%$ & \\
\hline & No & 0 & 63 & 17 & 1 & & \\
\hline & \multirow{3}{*}{ Total } & $0.0 \%$ & $77.8 \%$ & $21.0 \%$ & $1.2 \%$ & $100.0 \%$ & \\
\hline & & 40 & 140 & 37 & 1 & 218 & \\
\hline & & $18.3 \%$ & $64.2 \%$ & $17.0 \%$ & $.5 \%$ & $100.0 \%$ & \\
\hline
\end{tabular}

The results showed that the $33.3 \%(n=73)$ of studied STIs patients reached the PHC centers in 10 minutes or less, and $56.6 \%(n=124)$ reached by walking to obtain the health service. The analysis indicated the significant association of the time duration to reach the PHC centers to the received education and counseling on STIs, on condom, and for HIV testing [P value: 0.000 (2- sided) respectively]. Seventy-one percent $(n=153)$ did not pay for receiving the STIs services, and among those; $93.4 \%(n=111)$ aware of the free of charge nature of the service.

Table two reflecting that $57.5 \%(n=42)$ of those who reached the PHC center in ten minutes or less, and $71.4 \%$ $(n=45)$ of those who did not pay for receiving the service were satisfied with provided STIs service. The analysis indicated the significant association of the duration time to reach the PHC center, and pay for receiving the service to the overall satisfaction with provided STIs health service $[\mathrm{P}$ value: 0.000 (2- sided) respectively].

Table 2. Relationship between duration to reach the PHC center, paying for STIs services and the overall satisfaction of the provided STIs services at PHC centers in El-Damazin locality at BNS, $2015-2016(n=219)$.

\begin{tabular}{|c|c|c|c|c|c|c|c|}
\hline \multirow{2}{*}{ Details } & & \multicolumn{5}{|c|}{ Overall satisfaction of the provided service } & \multirow[b]{2}{*}{$P$ value } \\
\hline & & Very satisfied & Satisfied & Satisfied to some degree & Not satisfied & Total & \\
\hline \multirow{8}{*}{$\begin{array}{l}\text { Duration time to reach } \\
\text { the PHC center }\end{array}$} & 10 minutes or lesc & 25 & 42 & 6 & 0 & 73 & \multirow{8}{*}{.000} \\
\hline & 10 minutes or less & $34.2 \%$ & $57.5 \%$ & $8.2 \%$ & $0.0 \%$ & $100.0 \%$ & \\
\hline & 11 - 20 minutes & 11 & 60 & 19 & 0 & 90 & \\
\hline & $11-20$ mintules & $12.2 \%$ & $66.7 \%$ & $21.1 \%$ & $0.0 \%$ & $100.0 \%$ & \\
\hline & \multirow{2}{*}{$>20$ minutes } & 3 & 36 & 11 & 1 & 51 & \\
\hline & & $5.9 \%$ & $70.6 \%$ & $21.6 \%$ & $2.0 \%$ & $100.0 \%$ & \\
\hline & \multirow[t]{2}{*}{ Total } & 39 & 138 & 36 & 1 & 214 & \\
\hline & & $18.2 \%$ & $64.5 \%$ & $16.8 \%$ & $.5 \%$ & $100.0 \%$ & \\
\hline \multirow{6}{*}{$\begin{array}{l}\text { Paid for receiving the } \\
\text { STIs services }\end{array}$} & \multirow{2}{*}{ Yes } & 1 & 45 & 17 & 0 & 63 & \multirow{6}{*}{.000} \\
\hline & & $1.6 \%$ & $71.4 \%$ & $27.0 \%$ & $0.0 \%$ & $100.0 \%$ & \\
\hline & No & 39 & 93 & 20 & 1 & 153 & \\
\hline & No & $25.5 \%$ & $60.8 \%$ & $13.1 \%$ & $.7 \%$ & $100.0 \%$ & \\
\hline & \multirow[t]{2}{*}{ Total } & 40 & 138 & 37 & 1 & 216 & \\
\hline & & $18.5 \%$ & $63.9 \%$ & $17.1 \%$ & $.5 \%$ & $100.0 \%$ & \\
\hline
\end{tabular}

Figure three reflecting only $8.3 \%(n=18)$ of the studied STIs patients' rated the care provider - patient communication pattern as an excellent. Among those $94.4 \%$ $(n=17)$ were received education and counseling on condom, and $88.9 \%(n=16)$ were received education and counseling for HIV testing.

The analysis showed the significant association of the care providers-patients communication pattern to the received education and counseling on condom and for HIV testing [P value: 0.000 (2- sided) respectively].

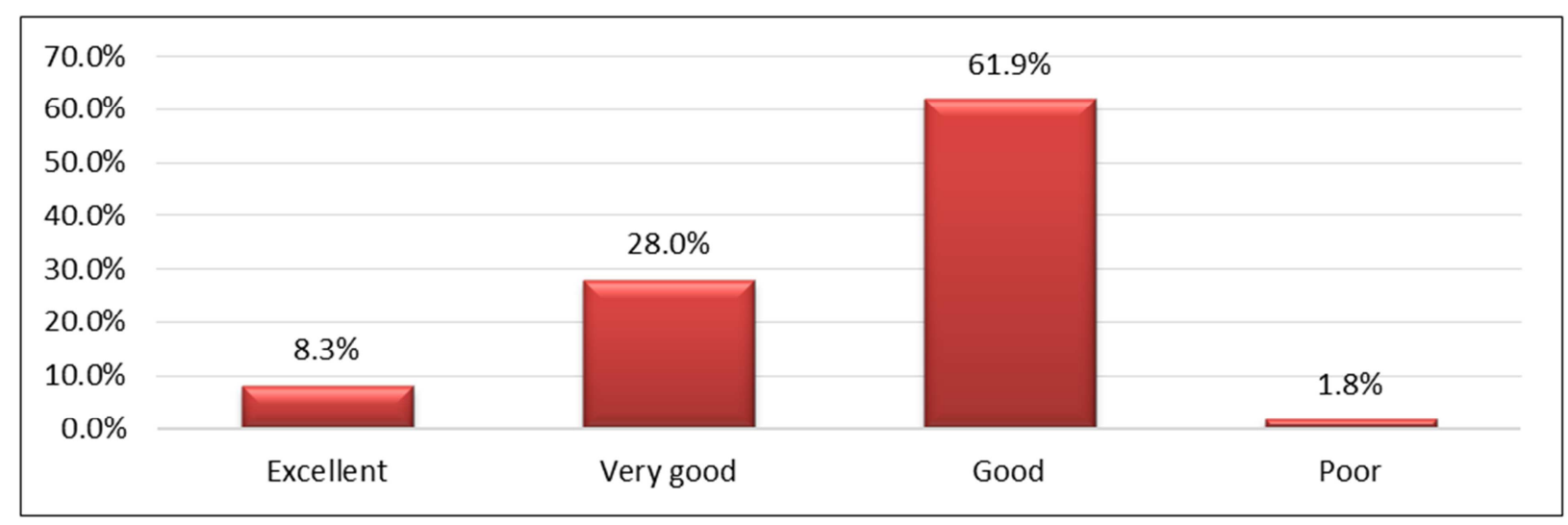

Figure 3. Rating of care providers-patients communication pattern at the PHC centers' in El-Damazin locality at BNS, 2015- 2016 (n=219). 


\section{Discussion}

This study is intended to assess the STIs patients' satisfaction with the provided STIs service at the PHC centers in El-Damazin. This study indiacted the majority of the studied patients were female, more than one third were below the age of 25 years, and one fourth were illiterate. The three findings are similar to Tanzania and Mongolia studies which indicated the sex, age and education are a factors associated with risk of acquiring STIs [8-9]. Also, Nathlee Samantha Abbai et al, indicated that the differences in the underlying causes and consequences of STIs infections in male and female, reflecting differences in biology, sexual behavior, social attitudes and pressures, economic power and vulnerability [7].

Despite the fact that the Sudan national guidelines for STIs service provision recommend the following components; a) treat the STIs patients by using STIs syndromic management approach, b) educate and counsel the STIs patients on condom and on HIV, c) counsel the STIs patients for HIV, and e) provide condom as prevention measure of STIs (Source: $C \& N C D C$ ), the recommended guidelines weren't applied during the study time. The findings revealed the considerable proportion of STIs patients did not receive all the components of STIs service, i.e. More than $50 \%$ of the single STIs patients did not receive education and counseling on condom, and more than $60 \%$ of the illiterate STIs patients did not receive education and counseling for HIV testing. Khalid, F. et al in their published paper's revealed that only $30 \%$ of the studied health CPs in the same study area and during the same study period were provided condom to the STIs patients, yet they provided condom without education or counseling to the service recipients [18]. Associating all above-mentioned findings together may indicate either that the taboo around STIs reduces access to the knowledge and information about STIs prevention measures or the health CPs providers stigmatize the recipients of STIs services or both factors combined. This results is similar to Khan. .^\#AA study in Pakistan, where he found that most of CPs were practicing personal pragmatism, and rarely following any standardized guidelines [19]. The good patients - care providers relationship is an important aspect in health that promote the service utilization, yet the above findings may indicate the cultural silence about STIs among the young patients act as a barrier for receiving such kind of service or this may indicate that the patients - care providers relationship at the PHC centers in Damazin is not sufficient to decrease the cultural silence for such group of patients. This may prevent them to discuss or to have proper education and counseling on STIs, condom or practicing safe sex especially with female and young patients. The above finding is similar to Kwazulu-Natal findings at South Africa [20].

In many ways, the high frequency of female STIs patients could be justified by the status of women in the society; e.g. inequity that women and girls suffer as a result of STIs serve as a barometer of their general status in society and the discrimination they encounter in all fields, including health, education, and employment. Due to women position they have difficulty in saying no sex or to unprotected sex since they are socially and economically dependent on male partners [20-23].

Though, more than half of the studied patients' were satisfied with the provided STIs service at PHC centers, the validation of this satisfaction those patients weren't fully aware of their rights to communicate and discussion about their case with health CPs, even how to deal with the community, and to have the all components of the STIs service as one package regardless their sex, age, marital status, and their education level.

\section{Conclusion}

Generally this paper revealed that the most of studied STIs patients were females. More than one third were at the age of 25 years or less and single. Most of studied patients stated that the PHC centers were accessible, and the service provided is affordable. More than half rated the patients-CPs communication pattern as good, yet more than half of the single STIs patients, and more than $40 \%$ of the young patients' did not receive education and counseling on condom. Also, this paper revealed that most of the illiterate patients did not receive education and counseling for HIV. This paper indicated the strong association of the received education and counseling on condom, education and counseling for HIV, access to service, affordability of service, and the patient-CPs communication pattern to the overall satisfaction of the provided service. More than $60 \%$ were satisfied with provided service, yet the validation of this satisfaction those clients were not fully aware of their rights to communicate and to discuss about their case with health CPs, even how to deal with the community, and to have the all components of STIs service as one package without discrimination. Therefore, increase the demand for the STIs service by increasing the awareness of the local community to the STIs service delivery components, STIs/HIV prevention measure is essential. Also, adoption of the rights based approach in the awareness raising will increase the demand on the STIs services components by decreasing the cultural silence about the STIs and selfstigma or stigma on health care setting.

\section{References}

[1] Christian. N and Janet. B. What are sexually transmitted infections? What are sexually transmitted disease? Medical News Today. Published: Jun 13, 2012; Updated: July 26, 2017.

[2] Burg. G. History of sexually transmitted infections (STIs). G Ital Dermatology Venereal. 2012 Aug; 127(4):329-40. PMID: 23007208 . 
[3] World Health Organization, Geneva, Switzerland. Sexual and reproductive health. Report on global sexually transmitted infection surveillance 2013. pp 54. ISBN: 9789241507400. Published: June, 2014.

[4] WHO. Guidelines for the Management of Sexually Transmitted Infections. Essential Medicines and Health Products Information Portal. WHO: 2001, page 88, Updated 2006.

[5] WHO, Global prevalence of selected available sexually transmitted infections. WHO; 2001 Nov.

[6] WHO. Sexual and reproductive health. Global Health Sector Strategy on Sexually Transmitted Infections 2016-2021. June 2016. 60 pages; Page, 12. WHO/RHR/16.09.

[7] Nathlee. A, Handan. W and Gita. R. Sexually Transmitted Infections in Women Participating in a Biomedical Intervention Trial in Durban: Prevalence, Coinfections, and Risk Factors. Journal of Sexually Transmitted Diseases. Volume 2013 (2013), Article ID 358402, 6 pages.

[8] Klouman. E, Masenga. EJ, Klepp. KI, Sam. NE, Nkya. W, Nkya. C. HIV and reproductive tract infections in a total village population in rural Kilimanjaro, Tanzania, women at increased risk. J Acquire Immune Defic Syndr Hum Retrovirol. 2007; 12:163-168. doi: 10.1097/00042560199702010-00010.

[9] Jantsansengeegiin. B, Jantsansengeegiin. B, Choijiljaviin. E, Jadambaagiin. N, Aumakhanii Bulbul, Jamsranjaviin. T, Erdenebatiin Dolgion, Erdenebaatariin Soyolmaa, Minjuuriin. E, Badrakhiin. J, Sodnomyn. O. Increasing syphilis notifications in Mongolia: results from national surveillance for 2001-2011. Western Pacific Surveillance and Response Journal, 2012, 3(4):86-93. doi:10.5365/wpsar.2012.3.2.008.

[10] Beyene. M, Gizachew. Y, Afework. K, Berihun. M, Shitaye. A, Bemnet. A, and Dagnachew. M. Sexually transmitted infections based on the syndromic approach in Gondar town, northwest Ethiopia. a retrospective study. BMC Public Health. 2013; 13: 123. Published online 2013 Feb 16. doi: 10.1186/1271-2458-13-123 PMCID: PMC3586370.

[11] UNFPA. HIV prevention and care for life. UNFPA Sudan/ fact sheet; 2012 Jul 23.

[12] UNAIDS.2010 UNGASS Report, North Sudan [internet]. SNAP; 2010 March 31.

[13] UNAIDS-Sudan. Global AIDS Response Progress Reporting $2012-2013$.
[14] Ali. M. M. Factors influencing healthcare service quality. International journal of health policy and management. Received 2012 Apr 26. Accepted 2012 Jul 21. Published online 2012 Jul 26.

[15] Farzana. A, Pranitha. M, Mohammed. YV. Interpersonal Relations between Health Care Workers and Young Clients: Barriers to Accessing Sexual and Reproductive Health Care. Health. February 2013, Volume 38, Issue 1, pp 150-155.

[16] Kathleen. JR. AIDS Patient Care and STDs. physician-Patient Relationships, Patient Satisfaction, and Antiretroviral Medication Adherence Among HIV-Infected Adults Attending a Public Health Clinic. July 2004, 16(1): 43-50.

[17] Weston. R, Dabis. R, Ross. JDC. Measuring patient satisfaction in sexually transmitted infection clinics: a systematic review. Sexually transmitted infections BMJ journal. Volume 85, issue 6.

[18] Khalid. F, Samia. H, Nada. O and Malaz. A. Factors Affecting the Utilization of Sexually Transmitted Infections Health Services at The Primary Health Centers in El-Damzin Locality at Blue Nile State, Sudan 2015-2016. World Journal of Public Health. Vol.3, No.2, 2018, pp 61-62. doi: 10.11648/j.wjph.20180302.15.Received: May 21, 2018; Accepted: June 6 2018; Published: July 12, 2018.

[19] A. Khan and A. Khan. Sexually transmitted infection care in Pakistan: the providers' perspective. Journal of the Pakistan Medical Association, vol. 62, no. 9, pp. 941-945, 2012.

[20] Zanakis. SH, Alvarez. C, Li V. Socio-economic determinants of HIV/AIDS pandemic and nation's efficiencies. European Journal for Operational Research, 2007; 176:1811-38. Received 26 August 2004; accepted 3 October 2005.

[21] Morris. M, Epstein. H, Wawer. M. Timing is everything: international variations in historical sexual partnership concurrency and HIV prevalence. PLoS One 2010; 5: e12092. 2. Published: November 24, 2010.

[22] Xu. JJ1, Wang. N, Lu L, Pu. Y, Zhang. GL, Wong. M, Wu. ZL, Zheng. XW. HIV and STIs in clients and female sex workers in mining regions of Gejiu City, China. National Center for AIDS/STD Control and Prevention. Sex Transm Dis. 2008 Jun; 35(6): 558-65. doi: 10.1097/OLQ.0b013e318165926b.

[23] WHO. 10 Facts on Sexually Transmitted Infections. World Health Organization, Geneva, Switzerland, 2013. 